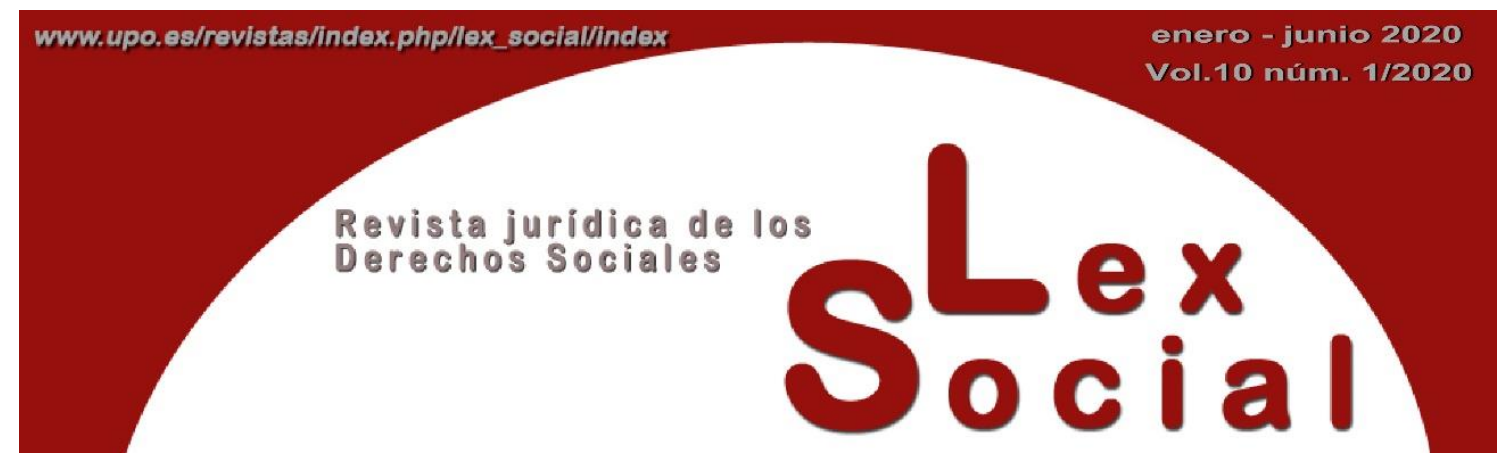

\title{
EL ALCANCE DE LA RESPONSABILIDAD SOLIDARIA PREVISTA EN EL ARTÍCULO 42 ET
}

THE JOINTLY AND SEVERAL LIABILITY EX SECTION 42 ET

LUIS ENRIQUE NORES TORRES ${ }^{1}$

Profesor Titular de Derecho del Trabajo y de la Seguridad Social

Universitat de València

Artículo recibido el 13 de noviembre de 2019

Artículo aceptado el 19 de noviembre de 2019

\begin{abstract}
RESUMEN
El artículo 42 ET impone sobre el empresario que contrata o subcontrata con otros la realización de obras o servicios pertenecientes a su propia actividad una responsabilidad solidaria sobre ciertas obligaciones contraídas por el contratista y el subcontratista con sus trabajadores, siempre que hayan nacido durante la vigencia de la contrata. En principio, el significado de la previsión normativa se presenta como relativamente sencillo; no obstante, su aplicación práctica suscita diferentes dudas interpretativas. Pues bien, el objeto de este trabajo se dirige a perfilar el contorno y contenido de la responsabilidad solidaria recogida en el art. 42 ET, lo que exige delimitar con claridad su ámbito de aplicación objetivo, subjetivo y temporal
\end{abstract}

Palabras Clave: Descentralización productiva, contratas de propia actividad, responsabilidad solidaria, plazos.

\footnotetext{
${ }^{1}$ Núm. orcid.org/0000-0001-6128-8552.
} 


\begin{abstract}
Section 42 ET sets up over the employer who outsource his production a joint and several liability on certain obligations contracted by the contractor and the subcontractor with their workers, but just in case that these obligations were born within the term of the outsourcing. At first, the meaning of the section seems fairly simple; however, its practical application raises differents questions and doubts. The purpose of this paper is to outline the contour and content of the joint and several liability ex section 42 ET.
\end{abstract}

KEYWORDS: Outsourcing, core business, jointly and several liability, terms.

\title{
SUMARIO
}

\section{I.- Introducción.}

II.-El alcance objetivo de la responsabilidad.

\section{Las obligaciones de naturaleza salarial.}

1.1. ¿El interés por mora?

1.2. ¿La liquidación por vacaciones y la de las pagas extraordinarias?

1.3. ¿La indemnización por fin de contrato?

1.4. ¿Los salarios de preaviso incumplidos?

1.5. ¿Los salarios de tramitación?

2. Las obligaciones de Seguridad Social.

III.- El alcance subjetivo de la responsabilidad.

IV.- El alcance temporal de la responsabilidad.

V.- Un breve apunte final: propuestas de mejora.

Bibliografía citada.

\section{INTRODUCCIÓN}

1.- Una de las características más sobresalientes que presenta el actual panorama productivo es, sin lugar a dudas, el recurso a maniobras descentralizadoras a la hora de organizar el proceso de producción ${ }^{2}$. Asimismo, tampoco ofrece demasiadas dudas el hecho de que entre las fórmulas de descentralización más extendidas se encuentran las que se articulan a través de las contratas y subcontratas de obras y servicios.

\footnotetext{
${ }^{2}$ Así, no es de extrañar que la Asociación Española de Derecho del Trabajo y de la Seguridad Social haya destinado a su estudio hasta dos congresos nacionales: por un lado, el X Congreso Nacional, celebrado en Zaragoza en 1999 bajo el título Descentralización productiva y nuevas formas organizativas del trabajo; por otro, el XXVIII Congreso Nacional, que tuvo lugar en Santiago de Compostela en 2018 bajo el título Descentralización productiva: nuevas formas de trabajo y organización empresarial.
} 
1.1.- Este modo de organizar el trabajo puede representar para los trabajadores implicados determinados riesgos o peligros. En este sentido, se suele destacar que, por un lado, tales trabajadores habitualmente contarán con unas condiciones laborales en su empresa inferiores a las que habrían disfrutado de estar ligados de forma directa con la empresa principal; por otro lado, en la medida en que la subcontratación tradicionalmente se ha efectuado hacia empresas endebles, el trabajador podría verse expuesto a un mayor riesgo de ver frustrados sus derechos laborales -sobre todo, los económicos- ante la posibilidad de que la contratista se coloque en situación de insolvencia ${ }^{3}$.

1.2.- Por ello, no es de extrañar que históricamente el ordenamiento jurídico haya tratado de dar una respuesta que conjure este tipo de riesgos a los que acabo de hacer referencia ${ }^{4}$.

Ciertamente, en un principio, los trabajadores involucrados en la descentralización no disponían de una tutela específica para ello, al margen de la acción directa prevista en el derecho común, en virtud de la cual podían obtener del comitente la satisfacción de las cantidades adeudadas por el contratista, eso sí, con el límite de lo que a éste adeudase el primero, tal y como dispone el art. 1597 del Código Civil.

Ahora bien, con el tiempo, aparecieron algunas previsiones de carácter específicamente laboral que abordaban el problema, prohibiendo las actividades meramente interpositorias de mano de obra y estableciendo un régimen de corresponsabilidad, más o menos limitado, entre las empresas implicadas. Estas previsiones pasaron con posterioridad al texto estatutario y no son otras que las recogidas hoy en día en los artículos 42 ET (subcontratación de obras y servicios) y 43 ET (cesión de trabajadores), a las se unió más adelante la Ley 14/1994, de 1 de junio, reguladora de las empresas de trabajo temporal.

El marco normativo de la subcontratación no se agota en lo anterior. Y es que, junto a las normas apenas mencionadas, hay que tener en cuenta también la normativa existente en materia de seguridad social -artículos 142 y 168 LGSS-, la de prevención de riesgos laborales -art. 24 LPRL- o la de carácter sancionador, tanto en el ámbito administrativo (arts. 23 y 42 LISOS), como penal (art. $315 \mathrm{CP}$ ), a las que se han unido otras normas de carácter más específico aplicables al sector de construcción -Ley 32/2006, de 18 de octubre, reguladora de la subcontratación en el sector de la construcción-.

2.- En todo caso, si nos centramos en la subcontratación de obras y servicios, el núcleo "duro" de la regulación viene constituido por el artículo 42 ET.

2.1.- Este precepto, al margen de imponer determinadas obligaciones informativas y documentales sobre los sujetos involucrados en los procesos descritos, también

\footnotetext{
${ }^{3}$ García Murcia, J. (1981), "El trabajo en contratas y la cesión de mano de obra en el Estatuto de los Trabajadores", Revista de Política Social, 130, p. 10; asimismo, Nores Torres, L.E. (2004), El trabajo en contratas. La noción de "contrata de propia actividad", Valencia, Tirant lo Blanch, pp. 22 y ss., y bibliografía allí citada.

${ }^{4}$ Al respecto, vid. Nores Torres, L. E. (2004: 25 y ss.). 
responsabiliza al empresario principal que contrata o subcontrata con otros la realización de obras o servicios pertenecientes a su propia actividad de ciertas obligaciones de naturaleza salarial y de Seguridad Social contraídas por el contratista y el subcontratista con sus trabajadores, siempre que hayan nacido durante la vigencia de la contrata.

2.2.- En principio, el significado de la previsión normativa se presenta como relativamente sencillo. Ahora bien, su aplicación práctica suscita diferentes dudas interpretativas que han provocado la intervención de los tribunales tratando de aclarar el alcance del precepto. Así las cosas, el objeto de este trabajo precisamente se dirige a perfilar el contorno y contenido de la responsabilidad solidaria recogida en el art. 42 ET, lo que exige delimitar con claridad su ámbito de aplicación objetivo, subjetivo y temporal.

\section{EL ALCANCE OBJETIVO DE LA RESPONSABILIDAD}

3.- En primer lugar, debe precisarse el alcance objetivo de esta responsabilidad. En este sentido, el art. 42 ET no establece una responsabilidad solidaria respecto cualquier obligación contraída por el contratista con sus trabajadores, sino que, de modo mucho más limitado, sólo la impone respecto las obligaciones de naturaleza salarial y de Seguridad Social nacidas durante la contrata.

3.1.- Ello implica que, en principio, se excluyen eventuales responsabilidades administrativas o penales ${ }^{5}$. Ahora bien, existen algunas responsabilidades administrativas que son comunicables:

- Así, por un lado, cabe mencionar una muy específica relacionada con la seguridad social, en concreto, la prevista en el art. 23.2 LISOS en relación con el art. 23.1.a): dar ocupación como trabajadores a beneficiarios o solicitantes de pensiones u otras prestaciones periódicas de la Seguridad Social cuyo disfrute sea incompatible con el trabajo por cuenta ajena, cuando no se les haya dado de alta con carácter previo al inicio de su actividad 6 .

- Por otro lado, las derivadas de incumplimientos en materia preventiva (art. 42.3 LISOS), en la medida en que la infracción de la normativa se haya producido en el centro de trabajo de la empresa principal ${ }^{7}$.

\footnotetext{
${ }^{5}$ Al respecto, entre otros, vid. Llano Sánchez, M. (1999), Responsabilidad empresarial en las contratas y subcontratas, Madrid, La Ley, pp. 173 y ss.

${ }^{6}$ En este punto resulta de interés la STSJ Extremadura de 11 de julio de 2017, rec. 3611/2017). Asimismo, en la doctrina, abordan esta específica cuestión con detalle, entre otros, López-Tarruella Martínez, F.; Viqueira Pérez, C. (2010), "Contratas y subcontratas: responsabilidad administrativa en materia de Seguridad Social”, en Blasco Pellicer, A. (Coord.), El empresario laboral, Valencia, Tirant lo Blanch, pp. 461 y ss.; Montoya Medina, D. (2018), "Subcontratación de obras y servicios y responsabilidad administrativa en materia de Seguridad Social”, en AEDTSS, Descentralización productiva: nuevas formas de trabajo y organización empresarial. XXVIII Congreso Nacional de Derecho del Trabajo y Seguridad Social, Madrid, CINCA (CD-ROM), 13 pp.

${ }^{7}$ El tema puede reconstruirse a través de los trabajos de, entre otros, Ramírez Martínez, J. M. (2002), "Las responsabilidades del empresario principal en las contratas y subcontratas”, en Pedrajas Moreno, A. (Dir.), La externalización de actividades laborales (outsourcing): una visión multidisciplinar, Valladolid, Lex Nova, pp. 163 y ss.; Gorelli Hernández, J. (2007), La tutela de los trabajadores ante la descentralización ISSN: 2174-6419 Lex Social, vol. 10, núm. 1 (2020)
} 
3.2.- Al margen de lo anterior, si nos centramos en el terreno de lo incluido, aún surgen determinadas dudas y problemas aplicativos que la jurisprudencia y la doctrina de suplicación han ido afrontando con mayor o menor éxito.

\section{Las obligaciones salariales}

4.- La alusión expresa a las obligaciones de naturaleza salarial implica que, por un lado, quedan integradas en el ámbito de la garantía todas aquellas percepciones de las que pueda predicarse dicho carácter, como pueden ser, claramente, las correspondientes al salario base, a los complementos salariales, a las horas extraordinarias o a las horas complementarias $^{8}$, mientras que, por otro lado, permanecen fuera del ámbito cubierto por la solidaridad todas aquellas deudas que deban reputarse "extrasalariales", esto es, cualquiera de los conceptos referidos en el art. 26.2 ET (indemnizaciones o suplidos por los gastos realizados como consecuencia de su actividad laboral, las prestaciones e indemnizaciones de la Seguridad Social y las indemnizaciones correspondientes a traslados, suspensiones o despidos $)^{9}$, como, por ejemplo, las dietas y gastos de combustible ${ }^{10}$.

4.1.- Obviamente, si los conceptos extrasalariales, en realidad, no fuesen tales, (así, por ejemplo, un plus de transporte abultado que enmascara la existencia de una partida salarial), la responsabilidad del principal llegaría hasta los mismos ${ }^{11}$, pero eso no desdice en nada la afirmación inicial que hemos adoptado como punto de partida, sino que, en realidad, la reafirma.

4.2.- Por otra parte, existen determinadas elementos retributivos cuya naturaleza, salarial o extrasalarial, ha sido discutida, lo que ha motivado la intervención de los tribunales para tratar de determinar si quedan incluidos o no en el ámbito protegido por la responsabilidad solidaria.

\section{1.- ¿El interés por mora?}

5.- Ello sucede, en primer lugar, con el interés por mora en el pago del salario al que alude el art. 29.3 ET, fijándolo en un diez por ciento de lo adeudado.

\footnotetext{
productiva, Madrid, Grupo Difusión, pp. 161 y ss.; Fernández López, Ma . F. (2018), "Las responsabilidades empresariales en el ámbito del trabajo en contratas", en AEDTSS, Descentralización productiva: Nuevas formas de trabajo y organización empresarial. XXVIII Congreso de Derecho del Trabajo y de la Seguridad Social, Madrid, CINCA, pp. 114 y ss.

${ }^{8}$ Al respecto, vid., Llano Sánchez, M. (1999: 229 y ss.), Folguera Crespo, J. (2000), "La responsabilidad salarial del empresario en contratas y subcontratas: su alcance objetivo", en Blat Gimeno, F. et altri, Descentralización productiva y protección del trabajo en contratas. Estudios en recuerdo de Francisco Blat Gimeno, Valencia, Tirant lo Blanch, pp. 203 y ss. o Montoya Medina, D. (2004), Trabajo en contratas y protección de los trabajadores, Valencia, Tirant lo Blanch, pp. 192-193; Viqueira Pérez, C. (2018), "Las responsabilidades laborales y de seguridad social en los supuestos de subcontratación”, en López Balaguer, M. (Coord.), Descentralización productiva y transformación del Derecho del Trabajo, Valencia, Tirant lo Blanch, p. 42; Fernández López, Mª. F. (2018: 111).

${ }^{9}$ Entre otros, Llano Sánchez, M. (1999: 234 y ss.); Folguera Crespo, J. (2000: 206); Montoya Medina, D. (2004: 190); Viqueira Pérez, C. (2018: 42-43).

${ }^{10}$ Entre otras, STSJ Galicia de 16 de diciembre de 2015, rec. 3493/2015.

${ }^{11}$ En este sentido, Llano Sánchez, M. (1999: 234); Montoya Medina, D. (2004: 191). 
5.1.- La doctrina de suplicación dictada a lo largo de los años noventa lo incluía sin mayor fundamento en el espacio protegido por la garantía del art. 42 ET o, a lo sumo, atendiendo a una concepción amplia del salario ${ }^{12}$. Y la misma tendencia se aprecia en otros pronunciamientos más recientes ${ }^{13}$. Asimismo, se podría traer como fundamento el art. 576 LEC, que si bien se refiere a los intereses procesales, justificaría que se diese la misma solución a los moratorios ${ }^{14}$.

5.2.- Con todo, si bien se mira, el interés por mora no deja de tener un cierto componente indemnizatorio, pues su objeto es compensar al trabajador por el retraso sufrido en la percepción de su salario desde la fecha del devengo y por ello alguna resolución judicial los ha excluido del ámbito del art. $42 \mathrm{ET}^{15}$.

\section{2.- ¿La liquidación por vacaciones y la de las pagas extraordinarias?}

6.- Una problemática similar ha generado la retribución correspondiente a las vacaciones, la cual claramente merece la consideración de salario, pues el art. 26.1 ET emplea una noción amplia de lo que el mismo sea y especifica que el concepto engloba la totalidad de percepciones económicas de los trabajadores, en dinero o en especie, por la prestación profesional de sus servicios, con independencia de que retribuyan el trabajo efectivo o los períodos de descanso computables como de trabajo. Esta misma idea se traslada actualmente por los tribunales al caso de la compensación económica por las vacaciones no disfrutadas, siendo un criterio asentado firmemente en la doctrina unificada el de su consideración como salario a efectos de las responsabilidades del art. $42 \mathrm{ET}^{16}$, superando orientaciones previas en las que se había sostenido un criterio diverso ${ }^{17}$.

6.1.- Así, la STS de 1 de febrero de 2006, rec. 3306/2004, afirma que: “Al respecto declaramos que el problema relativo a la naturaleza jurídica de las cantidades dedicadas a la liquidación de las vacaciones, debe abordarse desde las reglas que contiene el artículo 26 del Estatuto de los Trabajadores, en cuanto considera «salario la totalidad de las percepciones económicas de los trabajadores, en dinero o en especie, por la prestación profesional de los servicios laborales por cuenta ajena, ya retribuyan al trabajador efectivo, cualquiera que sea la forma de remuneración, o los períodos de descanso computables como de trabajo», y puesto que el tiempo destinado a vacaciones tiene la consideración de descanso computable como de trabajo, aunque realmente no se presten servicios mientras duran, la conclusión a la que se llega es que tales períodos de descanso no disfrutados por la extinción anticipada del contrato de trabajo, y que son compensados económicamente, la cantidad destinada a su remuneración es de

\footnotetext{
${ }^{12}$ Al respecto, vid. Montoya Medina, D. (2004: 201).

${ }^{13}$ STSJ Islas Canarias, Tenerife, de 13 de enero de 2017, rec. 1163/2015; SsTSJ Cataluña de 9 de octubre de 2017, rec. 3204/2017 y de 7 de noviembre de 2017, rec. 4180/2016; SsTSJ Madrid de 13 de diciembre de 2018, rec. 204/2018 y de 11 de febrero de 2019, rec. 1286/2018.

${ }^{14}$ Montoya Medina, D. (2004: 202-203).

15 STSJ Comunidad Valenciana de 17 de mayo de 2012, rec. 3167/2011 o, parece, la STSJ Asturias de 27 de diciembre de 2017, rec. 2393/2017

${ }^{16}$ SsTS de 23 de diciembre de 2004, rec. 4525/2003, de 9 de marzo de 2005, rec. 6537/2003, de 31 de enero de 2006, rec. 4895/2004), de 1 de febrero de 2006, rec. 3306/2004, de 27 de abril de 2006, rec. 112/2005, de 24 de abril de 2006, rec. 112/2015; más reciente, la STS de 11 de noviembre de 2013, rec. 2674/2012.

${ }^{17}$ La problemática aparece recogida en Llano Sánchez, M. (1999: 234).
} 
naturaleza salarial y no indemnizatoria Por consiguiente, al seguir la sentencia recurrida la doctrina proclamada por aquella sentencia de esta Sala y las de 20 de mayo de 1998 ( RJ 1998, 4738) y 9 de julio de 2002 ( RJ 2002, 10538), resolvió el debate con ajuste al ordenamiento, careciendo de contenido casacional el presente motivo del recurso".

6.2.- Algunos autores han discrepando en el caso de la compensación relativa a las no disfrutadas, pues le asignan un carácter indemnizatorio ${ }^{18}$. A mi juicio, sin embargo, la opinión no es compartible. Y es que, al margen de la existencia de una jurisprudencia tan asentada en la materia en sentido contrario, creo que se trata de cantidades salariales adeudadas y que, por tanto, se integran en el ámbito de la responsabilidad solidaria del art. $42 \mathrm{ET}$, salvo que aún se puedan disfrutar como ha afirmado algún pronunciamiento dictado en suplicación ${ }^{19}$. Ello nos introduce en la conveniencia de introducir ciertos matices a la respuesta general, fijándonos en otros aspectos relevantes, como pueden ser el momento en que se produce la suscripción de la contrata o su extinción, algo que no abordan las sentencias antes citadas.

a) Así, de entrada, cabe imaginar que la contrata estuviese aún vigente en el momento de surgir el derecho, esto es, la extinción del contrato se produce estando la contrata viva y sin haberse disfrutado aún las vacaciones. Aquí, el empresario principal sería responsable, pues estamos ante una obligación de naturaleza salarial nacida durante la vigencia de la contrata y que, en consecuencia, se reconduce al terreno de lo protegido por el art. $42 \mathrm{ET}$.

b) Ahora bien, más complejo resulta cuando la contrata ha estado vigente a lo largo del nacimiento del derecho a las vacaciones, pero finalizó con anterioridad al disfrute de las mismas o a la extinción del contrato. Así, por ejemplo, una contrata que finalizase en mayo, extinguiéndose el contrato en julio estando pendiente el disfrute de las vacaciones. Aquí, en principio, podría entenderse que el empresario principal no asume responsabilidad alguna, pues la obligación habría nacido con posterioridad a la finalización de la contrata; con todo, a mi juicio, la respuesta no debería ser tan automática y debería considerarse la posibilidad de que el comitente respondiese, al menos, de la parte proporcional, algo que parece intuirse en algún pronunciamiento dictado en suplicación ${ }^{20}$. Una duda parecida se plantea en la situación inversa, es decir, cuando la contrata nace habiéndose generado las vacaciones con anterioridad a la suscripción de aquélla.

7.- Un problema similar, a mi juicio, se puede suscitar en relación con las pagas extraordinarias.

7.1.- En este sentido, piénsese en una contrata cuya vigencia, por ejemplo, finaliza en mayo, estando prevista la paga extra para el mes de junio. El TS, en relación con una contrata extinguida un seis de junio, excluyó la responsabilidad solidaria respecto la paga extraordinaria de junio al entender que se trataba de una obligación nacida con

\footnotetext{
${ }^{18}$ Montoya Medina, D. (2004: 204-205).

${ }^{19}$ STSJ Madrid de 11 de febrero de 2019, rec. 1286/2014.

${ }^{20}$ STSJ Cataluña de 9 de octubre de 2017, rec. 3204/2017. 
posterioridad a la contrata ${ }^{21}$. No obstante, en estos casos, cabría entender que, en realidad, la obligación se ha ido generando durante la vigencia de la contrata, pues las pagas extraordinarias se generan día a día, como el propio TS tiene señalado. Así pues, a mi juicio, la empresa principal debería responsabilizarse proporcionalmente.

7.2.- En fin, nuevamente, al igual que en relación con las vacaciones, cabría plantearse la situación inversa: la contrata se suscribe a inicios del mes de junio, cuando la paga extraordinaria ya se ha generado y la contratista no la abona. A mi juicio, y por coherencia con el razonamiento anteriormente desarrollado, a pesar de tratarse de una obligación de naturaleza salarial, el comitente no debería asumir responsabilidades $-\mathrm{o}$, tan solo, de manera proporcional, en su caso-, pues en realidad la obligación ha nacido con anterioridad a la aparición de la contrata.

\section{3.- ¿La indemnización por fin de contrato?}

8.- Una tercera partida problemática ha sido y es la relativa a las indemnizaciones por fin de contrato.

8.1.- De entrada, debe tenerse en cuenta que el art. 26.2 ET tan solo niega el carácter salarial a las indemnizaciones por traslado, suspensión del contrato y despido. Por ello, la doctrina de suplicación dictada en los años noventa habitualmente rechazaba el carácter extrasalarial de estas específicas compensaciones y las integraba en el espacio protegido por el art. $42 \mathrm{ET}^{22}$. Esta interpretación, con toda seguridad, estaba influenciada por el hecho de que, en ese momento, las indemnizaciones por fin de contrato temporal no estaban previstas en el texto estatutario, sino que eran obra del convenio colectivo y podían entenderse como una suerte de salario diferido.

8.2.- Con todo, también existían pronunciamientos en sentido contrario ${ }^{23}$. Y es que, en el fondo, no puede negarse que estas partidas tienen una finalidad compensatoria, al margen de que van vinculadas a la extinción del contrato; de hecho, la doctrina de suplicación más reciente se mueve por esta línea y las considera excluidas de la responsabilidad solidaria ${ }^{24}$.

\section{4.- ¿Los salarios del preaviso incumplido?}

9.- Otro supuesto que ha generado ciertas dudas interpretativas es el que se ha planteado en el terreno de los despidos objetivos en relación con el abono de los días de preaviso incumplidos.

9.1.- La doctrina científica había defendido su exclusión sobre la base de dos argumentos principales: por un lado, la reconducción de estas partidas a las indemnizaciones por despido a las que alude el art. 26.2 ET para excluirlas de la

\footnotetext{
${ }^{21}$ STS de 11 de noviembre de 2013, rec. 2674/2012; en la misma línea se mueve la STSJ País Vasco de 28 de febrero de 2012, rec. 315/2012.

${ }^{22}$ Al respecto, vid. MONTOYA MEDINA, D. (2004: 198-199).

${ }^{23}$ Ibidem.

${ }^{24}$ SsTSJ Andalucía, Sevilla, de 5 de julio de 2012, rec. 1818/2011 y rec. 3794/2011; STSJ Galicia de 16 de diciembre de 2015, rec. 3493/2015; STSJ Islas Canarias, Tenerife, de 5 de diciembre de 2017; STSJ Madrid de 11 de febrero de 2019, rec. 1286/2018.
} 
consideración de salario; por otro lado, desde la perspectiva de que tendrían un evidente carácter indemnizatorio, ya que tratarían de compensar el daño producido por la resolución imprevista e inminente del vínculo contractual cuando no se ha respetado el plazo de quince días impuesto por el art. 53 ET para este tipo de extinciones ${ }^{25}$. Y en este mismo sentido se ha movido también alguna sentencia dictada en suplicación ${ }^{26}$.

9.2.- Con todo, no se trata de una orientación unánime, pues algunos pronunciamientos han ofrecido argumentos en sentido diverso y defendido la inclusión de estas partidas en el ámbito de lo protegido por el artículo $42 \mathrm{ET}^{27}$. En este sentido, por un lado, se subraya la necesidad de tener en cuenta que el art. 53 ET los configura como salario; de hecho, el art. 53.4 ET alude a la obligación de "abonar los salarios correspondientes a dicho período". Por otro lado, estas resoluciones aluden a unas sentencias del Tribunal Supremo (en concreto, las SsTS de 2 y 10 de febrero de 2010, rec. 1908/09 y 1587/09) en las que, a pesar de excluirlos de la responsabilidad del FOGASA, se afirma que tienen naturaleza salarial, pues se abonan al margen de la indemnización; así, si el despido es nulo o improcedente, y se produce la readmisión, los salarios de preaviso no se devuelven, a diferencia de aquélla. Esta idea manejada por el Tribunal Supremo se refuerza aún más si tenemos en cuenta el distinto tratamiento que tienen la indemnización y el preaviso a la hora de valorar la calificación del despido: la falta de entrega de la primera acarrea la improcedencia del acto extintivo, no así el incumplimiento del segundo. Ahora bien, sabemos que la cuestión de la naturaleza de una determinada partida nunca es decisiva; y lo sabemos, precisamente, por otra partida tradicionalmente controvertida: los salarios de tramitación.

\section{5.- ¿Los salarios de tramitación?}

10.- La discusión sobre la naturaleza jurídica de los salarios de tramitación, salarial o indemnizatoria, ha constituido un clásico en la doctrina y en la jurisprudencia, de manera especial en dos terrenos: por un lado, a la hora de delimitar el alcance de la cobertura protectora del FOGASA cuando el art. 33 ET alude a los "salarios"; por otro, precisamente en este de la determinación de las deudas cubiertas por la responsabilidad solidaria prevista en el art. $42 \mathrm{ET}^{28}$.

10.1.- Finalmente, el Tribunal Supremo se decantó por atribuirles una naturaleza propia, con vertientes salariales e indemnizatorias, pero que, en todo caso, quedaban excluidos de la cobertura del art. $42 \mathrm{ET}^{29}$.

\footnotetext{
${ }^{25}$ Montoya Medina, D. (2004: 198).

${ }^{26}$ STSJ Madrid de 11 de febrero de 2019, rec. 1286/2018.

${ }^{27}$ SsTSJ Islas Canarias, Tenerife, de 14 de enero de 2014, rec. 430/2013 y rec. 491/2013.

${ }^{28} \mathrm{Al}$ respecto, vid. Gárate Castro, J. (1994), Los salarios de tramitación. Un estudio sobre las percepciones salariales unidas a la declaración de improcedencia o nulidad del despido, Madrid, ACARL, pp. 61-66; Altés Tárrega, J. (1998), "La naturaleza jurídica de los salarios de tramitación: ¿al fin una cuestión resuelta?, Relaciones Laborales, 2, pp. 122 y ss.; Llano Sánchez, M. (1999: 236-237); Gala Durán, C. (2001), "La responsabilidad en materia salarial en el ámbito de las contratas y subcontratas", en Del Rey Guanter, S. (Dir.), Descentralización productiva y relaciones laborales: problemática jurídica actual, Valladolid, Lex Nova, pp. 232 y ss.

${ }^{29}$ SsTS u.d. de 14 de julio de 1998, rec. 3482/1997 y de 9 de diciembre de 1999, rec. 1116/1999. 
10.2.- Las reformas normativas habidas a lo largo del año 2001 y 2002 reabrieron el debate, pero el Tribunal Supremo sigue manteniendo su postura ${ }^{30}$, con la merecida crítica doctrinal $^{31}$.

\section{2.- Las obligaciones de Seguridad Social}

11.- El art. 42 ET también extiende la responsabilidad solidaria a las obligaciones en materia de seguridad social nacidas durante la vigencia de la contrata, pudiéndose exigir durante los tres años siguientes a su finalización ${ }^{32}$.

11.1.- Un primer aspecto a destacar, como se ha encargado de remarcar la doctrina judicial $^{33}$ y científica ${ }^{34}$, es la diferencia entre esta previsión y las contenidas en los arts. 142 y 168 LGSS, ya que se trata de una responsabilidad distinta y adicional a las contenidas en estos últimos preceptos. Y es que, en efecto, las previsiones contenidas en la LGSS contemplan una responsabilidad en la que es distinta la naturaleza (subsidiaria y no solidaria), los sujetos responsables (cualquier contratista, con independencia de que la actividad pertenezca a la propia actividad del principal o no) y los límites (no opera la exoneración que contempla el art. 42 ET ante el silencio a la solicitud de certificación de descubiertos).

11.2.- En segundo lugar, también debe remarcarse que la aplicación de las previsiones contenidas en el texto estatutario parece encontrarse condicionada al cumplimiento o no de una obligación formal impuesta por el propio artículo 42.1 ET: la petición por parte del empresario principal de un certificado negativo de descubiertos a la Seguridad Social ${ }^{35}$.

\footnotetext{
${ }^{30}$ STS de 20 de febrero de 2006, rec. 506/2005.

${ }^{31}$ Viqueira Pérez, C. (2018: 42-43).

${ }^{32}$ Sobre la cuestión, vid. Monereo Pérez, J. L. (1992), "El ámbito material de la responsabilidad en el trabajo en contratas. Las obligaciones "referidas" a la Seguridad Social", Relaciones Laborales-II, 265 y ss.; López Gandía, J.; Tatay Puchades, C. (2000), "Contratas y subcontratas y responsabilidades de Seguridad Social", en Blat Gimeno, F. et altri, Descentralización productiva y protección del trabajo en contratas. Estudios en recuerdo de Francisco Blat Gimeno, Valencia, Tirant lo Blanch, pp. 227 y ss.; Luque Parra, M. (2001), "La responsabilidad empresarial en materia de Seguridad Social en el ámbito de las contratas y subcontratas de obras y servicios", en Del Rey Guanter, S. (Dir.), Descentralización productiva y relaciones laborales: problemática jurídica actual, Valladolid, Lex Nova, pp. 217 y ss.; Aragón Sánchez, C. (2018), "Las responsabilidades de la empresa principal con respecto a las obligaciones de la empresa contratista en materia de Seguridad Social", en AEDTSS, Descentralización productiva: nuevas formas de trabajo y organización empresarial. XXVIII Congreso de Derecho del Trabajo y de la Seguridad Social, Madrid, CINCA (CD-ROM), 12 pp.

${ }^{33}$ Al respecto vid. STS 23 de septiembre de 2008, rec. 1048/2007, y de 9 de diciembre de 2010, rec. 1266/2010; igualmente, la STSJ Cataluña de 8 de mayo de 2012, rec. 7386/2011.

${ }^{34}$ Llano Sánchez, M. (1999: 277 y ss.); Montoya Medina, D. (2004: 299 y ss.); Gorelli Hernández, J. (2007: 159-160); Aragón Gómez, C. (2018: 2-3).

${ }^{35}$ Sobre el tema, Llano Sánchez, M. (1999: 182 y ss.); Camps Ruiz, L. M. (2000), "La obligación empresarial de comprobar la solvencia del contratista o subcontratista: significado y consecuencias", en Blat Gimeno, F. et altri, Descentralización productiva y protección del trabajo en contratas. Estudios en recuerdo de Francisco Blat Gimeno, Valencia, Tirant lo Blanch, pp. 243 y ss.; De Val Tena, A. L. (2018), "Exoneración de responsabilidad del empresario principal ante el incumplimiento de las obligaciones de Seguridad Social por os contratistas y subcontratistas: sobre los efectos de la certificación negativa de descubiertos librada por la Tesorería General de la Seguridad Social", en en AEDTSS, Descentralización productiva: nuevas formas de trabajo y organización empresarial. XXVIII Congreso de Derecho del Trabajo y de la Seguridad Social, Madrid, CINCA, CD-ROM, 12 pp.
} 
a) De entrada, a pesar del tenor literal, debe señalarse que no estamos ante una verdadera obligación del empresario principal, sino más bien ante una facultad que le permitirá comprobar si el contratista se encuentra al corriente o no de sus pagos a la seguridad social ${ }^{36}$.

b) Por otra parte, el texto estatutario no especifica el momento en que debe solicitarse el certificado; aún así, parece razonable entender que se solicitará antes de concertar la contrata, si bien no estamos ante una cuestión pacífica ${ }^{37}$, como tampoco lo es si nos encontramos ante una obligación de tracto único o, diversamente, de tracto sucesivo $^{38}$.

c) A partir de ahí, cabe imaginar las siguientes posibilidades ${ }^{39}$ : en primer lugar, que la solicitud no se efectúe, en cuyo caso no operará la exoneración; en segundo lugar, que se efectúe, se obtenga una respuesta afirmativa sobre la existencia de descubiertos y, pese a ello, la empresa principal suscriba la contrata, supuesto en el que tampoco, obviamente, se producirá exoneración alguna; en tercer lugar, que tras efectuar la solicitud, la TGSS no conteste en el plazo de treinta días, siendo esta la situación a la que el ET anuda el efecto exoneratorio; el mismo efecto, en cuarto lugar, cabe anudar, pese al silencio normativo, a los supuestos en los que se ha cursado la solicitud y se libra por la TGSS una certificación negativa sobre la existencia de descubiertos.

12.- En todo caso, el núcleo de la discusión que genera la previsión normativa analizada versa, sin duda alguna, sobre el alcance objetivo de la responsabilidad que asume el empresario principal en materia de Seguridad Social ${ }^{40}$.

12.1.- En primer lugar, y esto no genera mayores discusiones, la responsabilidad establecida en el art. 42.2 ET integra no solo las obligaciones jurídico públicas "con" la Seguridad Social, relacionadas con los deberes de afiliación, alta y cotización, sino también las relativas a las prestaciones, eso sí, en dos supuestos específicos ${ }^{41}$ : por un lado, cuando el empresario haya sido declarado responsable de las mismas por incumplimiento de sus deberes de afiliación, alta o cotización; por otro, cuando la empresa contratista hubiese incumplido la obligación de pago delegado.

12.2.- En segundo lugar, a pesar de que el precepto alude a las obligaciones referidas a la Seguridad Social y no "con la Seguridad Social", es decir, empleando una noción "objetiva" y no de carácter "subjetivo", lo que podría permitir integrar en el espacio protegido las mejoras voluntarias ${ }^{42}$, lo cierto es que la jurisprudencia unificada

\footnotetext{
${ }^{36}$ Así, por ejemplo, Cruz Villalón, J. (1992), “Descentralización productiva y responsabilidad laboral por contratas y subcontratas", Relaciones Laborales-I, p.16; Llano Sánchez, M. (1999: 184-185).

${ }^{37}$ Al respecto, vid. Llano Sánchez, M. (1999: 188); Camps Ruiz, L. M. (2000: 252-253).

${ }^{38}$ Sobre el tema, vid. Camps Ruiz, L. M. (2000: 256-258) o De Val Tena, A. L. (2018: 7).

${ }^{39}$ Llano Sánchez, M. (1999: 199 y ss.); Camps Ruiz, L. M. (2000: 253-256).

${ }^{40} \mathrm{Al}$ respecto, vid., entre otros, Llano Sánchez, M. (1999: 241 y ss.); López Gandía, J.; Tatay Puchades, C. (2000: 228-235); Montoya Medina, D. (2004: 219 y ss.); Gorelli Hernández, J. (2007: 154 y ss.).

${ }^{41}$ Monereo Pérez, J. L. (1992: 271).

${ }^{42}$ Monereo Pérez, J. L. (1994), La responsabilidad empresarial en los procesos de subcontratación, Madrid, Ibidem, pp. 133 y ss.; López Gandía, J.; Tatay Puchades, C. (2000: 231); Ramírez Martínez, J. M. (2002: 162).
} 
ha dejado al margen de la responsabilidad solidaria derivada del art. 42 ET tales $\operatorname{conceptos}^{43}$. En efecto, el Tribunal Supremo tiene señalado que el art. 42.2 ET se refiere a deudas contraídas con la Seguridad Social como ente gestor de prestaciones y no con los trabajadores en dicha específica materia, empleando como argumentos para sostener esta postura, por un lado, la autonomía del derecho de la Seguridad Social; por otro, el hecho de que la solidaridad se debe establecer de forma expresa, algo que aquí no se cumpliría; igualmente, la no operatividad del principio de automaticidad; en fin, se alude también al hecho de que estaríamos ante una percepción derivada del contrato de trabajo que, al versar sobre seguridad social, quedaría integrada en los conceptos extrasalariales mencionados por el art. $26.2 \mathrm{ET}^{44}$.

12.3.- Finalmente, habría que hacer referencia a los recargos de prestaciones por incumplimiento de las medidas de seguridad en el trabajo ${ }^{45}$.

Estos recargos, atendiendo a su discutida naturaleza jurídica, quedarían fuera de la protección dispensada por el art. 42 ET: si se les atribuyera una naturaleza sancionadora, por los principios de responsabilidad personal que rigen la materia punitiva; si, diversamente, se les considerase resarcitorios, por su naturaleza indemnizatoria.

Ahora bien, en ciertos casos, sí que se van a ser objeto de extensión, pero se trata de supuestos previstos expresamente por el legislador que requieren de la concurrencia de unos requisitos específicos: de entrada, que se trate de contratas pertenecientes a la propia actividad; por otro lado, que se ejecuten en el mismo centro de trabajo; en fin, que los empresarios implicados hayan incumplido la normativa preventiva. Así nos lo recuerda la jurisprudencia, en aplicación de las previsiones contenidas en los arts. 164 LGSS, 43 LISOS y 24 LPRL $^{46}$; desde la perspectiva inversa, cuando el principal ha cumplido con sus deberes, no se produce la extensión de la responsabilidad ${ }^{47}$.

\section{III.- EL ALCANCE SUBJETIVO DE LA RESPONSABILIDAD}

13.- El hecho de que el art. 42 ET aluda genéricamente a la existencia de una responsabilidad solidaria de la empresa principal y que el art. 42.2.II ET mencione las obligaciones contraídas por el contratista con sus trabajadores podría inducir a pensar que la responsabilidad alcanza o beneficia a todos ellos. No obstante, la doctrina no ha tenido

\footnotetext{
${ }^{43}$ SsTS 19 de mayo de 1998, rec. 3797/1997, de 16 de septiembre de 1999, rec. 2587/1998, de 14 de febrero de 2000, rec. 181/1999 y 22 de diciembre de 2000, rec. 4069/1999.

${ }^{44}$ Llano Sánchez, M. (1999: 244 y ss.); Montoya Medina, D. (2004: 231 y ss.); Gorelli Hernández, J. (2007: 157).

${ }^{45}$ Montoya Medina, D. (2004: 241 y ss.).

${ }^{46}$ STSJ Galicia de 31 de marzo de 2015, rec. 1842/2015; STSJ Cataluña de 15 de noviembre de 2016, rec. 4531/2016; STSJ Andalucía, Sevilla, de 15 de diciembre de 2016, rec. 3424/2015; STSJ País Vasco de 4 de abril de 2017, rec. 568/2017.

47 STSJ Andalucía, Sevilla, de 6 de abril de 2017, rec. 1316/2016; STSJ Cataluña de 11 de julio de 2017, rec. $2977 / 2017$.
} 
grandes dificultades en afirmar que ello hay que entenderlo referido únicamente a aquellos trabajadores que estén adscritos a la contrata ${ }^{48}$.

13.1.- Esta orientación viene avalada por la doctrina de suplicación ${ }^{49}$. Así, por ejemplo, se ha negado la extensión de responsabilidades en el caso una contrata del sector de la construcción perteneciente a la propia actividad de la principal por tratarse de un trabajador que desarrollaba tareas de administrativo en la contratista, pero que no participaba en la obra contratada ${ }^{50}$. Por otra parte, algún pronunciamiento ha matizado aún más esta exigencia y entiende que la responsabilidad solidaria se impone, en su caso, tan sólo respecto los trabajadores adscritos a la contrata y por el tiempo de adscripción a la misma ${ }^{51}$, en línea con lo propugnado en sede doctrinal ${ }^{52}$. Y para ello, para comprobar el alcance de la responsabilidad en función de la adscripción o no a la contrata, muestran una gran utilidad los derechos de información y documentación a los que alude el art. 42 ET. Por lo demás, la carga de la prueba sobre tal extremo, en aplicación de las reglas sobre la facilidad probatoria, se desplaza hacia la empresa, al menos en los casos en que se afirma una adscripción parcial o temporal ${ }^{53}$.

13.2.- Ahora bien, al margen de lo anterior, la práctica judicial nos evidencia que la respuesta no es siempre tan sencilla, pues en ocasiones la prestación laboral no se ejecuta de manera directa en la contrata, pero sí que está conectada o vinculada especialmente con la misma y, en tales casos, también nace la responsabilidad solidaria. Así, por ejemplo, en el caso de una empresa que lleva a cabo la ejecución de una carretera y que contrata con otra las labores de movimiento de tierras -algo que constituye, claramente, una contrata perteneciente a la propia actividad-, la doctrina de suplicación brinda ejemplos de extensión de la responsabilidad solidaria respecto unas obligaciones salariales planteadas por unos administrativos, porque sus tareas habían sido mayoritariamente de documentación y administrativas inherentes a la obra $^{54}$.

\section{IV.- EL ALCANCE TEMPORAL DE LA RESPONSABILIDAD}

14.- Por último, el art. 42 ET también establece una serie de límites temporales a todas este conjunto de responsabilidades. En este sentido, recuérdese que el empresario principal tan solo responde de las obligaciones nacidas durante la vigencia de la contrata y que el plazo para exigirlas es de un año a contar a partir de la finalización del encargo, eso sí, siempre que la acción principal no se encuentre extinguida.

\footnotetext{
${ }^{48}$ Entre otros, Llano Sánchez, M. (1999: 255 y ss.); Montoya Medina, D. (2004: 288 y ss.).

49 STSJ Asturias de 7 de febrero de 2017, rec. 3036/2016; STSJ Andalucía, Sevilla, de 30 de marzo de 2017, rec. 1233/2016; SsTSJ Islas Canarias, Tenerife, de 6 de octubre de 2017, rec. 181/2017 y de 9 de abril de 2019, rec. 368/2019.

${ }^{50}$ STSJ Murcia 23 de marzo de 2010, rec. 1004/2009, STSJ Navarra 25 de enero de 2010, st. 23/2010, STSJ

La Rioja 13 de septiembre de 2012, rec. 233/2012

${ }^{51}$ SsTSJ Cataluña de 23 de marzo de 2015, rec. 6191/2014, de 24 de abril de 2015, rec. 407/2015 o de 9 de octubre de 2017, rec. 3204/2007.

${ }^{52}$ Gala Durán, C. (2001: 231).

${ }^{53}$ STSJ Cataluña de 24 de abril de 2015, rec. 407/2015.

${ }^{54}$ SsTSJ Murcia de 17 de diciembre de 2012 y 26 de diciembre de 2012, rec. 780/2012 y 724/2012. 
15.- De entrada, en relación con las obligaciones nacidas durante la vigencia de la contrata, ya he aludido anteriormente a los problemas que se pueden suscitar en este terreno (vid. supra §6): por un lado, aquellas obligaciones que se generan durante la vigencia de la contrata, pero que se devengan tras su extinción; por otro, aquellas obligaciones generadas antes de la suscripción de la contrata pero que se devengan cuando ésta ya está vigente.

15.1.- Al respecto, ya he señalado como en el primer caso debería extenderse la responsabilidad de manera proporcional al empresario principal a pesar de que la deuda sea posterior a la contrata, como parece haber apuntado algún pronunciamiento dictado en suplicación ${ }^{55}$.

15.2.- Igualmente, en la misma sede, se ha matizado que "hasta la finalización" de la contrata no equivale hasta el cese de trabajo efectivo cuando este tiene lugar con carácter previo al inicialmente previsto ${ }^{56}$.

16.- Al margen de lo anterior, hay otra cuestión por la que normalmente se ha pasado de puntillas y que, sin embargo, genera importantes dudas interpretativas, especialmente en los últimos tiempos. Me refiero al plazo de un año (tres en materia de Seguridad Social) durante el cual está viva la responsabilidad solidaria del empresario principal.

16.1.- En este punto, tradicionalmente se han barajado dos grandes interpretaciones ${ }^{57}$.

a) Por un lado, que estamos ante una reiteración respecto lo establecido en el art. 59 ET. Así, el plazo general de un año previsto en el art. 59 ET regiría también aquí, eso sí, en la medida en que la acción no hubiese prescrito con anterioridad; es decir, se trataría de una previsión absolutamente superflua.

b) Por otro lado, la segunda opción pasaría por entender que estamos ante un plazo que presenta un carácter autónomo: el empresario principal responde de las deudas pendientes durante el año siguiente a la terminación de la contrata, lo cual carece de sentido, pues por esta vía la responsabilidad del empresario principal tendría una mayor perdurabilidad en el tiempo que la del empresario contratista.

Alguna sentencia dictada en suplicación, tras recoger ambas interpretaciones, se había decantado de manera rotunda por la primera opción: "al establecer el art. 42 que la obligación del empresario comitente es exigible durante el año siguiente a la terminación de su encargo, parece que admite la posibilidad de exigir deudas salariales del contratista que ya estuvieran prescritas antes de la finalización de la contrata, pues, en otro caso no sería más que una reiteración indeseada de lo preceptuado en el art. 59 del

\footnotetext{
55 STSJ Cataluña de 9 de octubre de 2017, rec. 3204/2017.

56 STSJ Cataluña de 30 de septiembre de 2015, rec. 3417/2015; en doctrina, Roqueta Buj, R. (2002),

"Alcance temporal de las responsabilidades", en Blat Gimeno, F. et altri, Descentralización productiva y protección del trabajo en contratas. Estudios en recuerdo de Francisco Blat Gimeno, Valencia, Tirant lo Blanch, pp. 263 y ss.

${ }^{57}$ Gala Durán, C. (2001: 240); Montoya Medina, D. (2004: 234). 
E.T. Como ello supondría imponer una obligación más intensa al empresario principal que al contratista empleador directo del trabajador, debe ser rechazada equiparando ambas responsabilidades en el tiempo en que pueden ser exigidas" ${ }^{25}$.

16.2.- A mi juicio, los términos del debate se movían por unos senderos un tanto erróneos. En efecto, aunque la idea de partida sobre que la "responsabilidad" del empresario principal se extiende durante el año siguiente a la finalización de la contrata, eso sí, en la medida en que las "acciones" no estén prescritas, resulta acertada ${ }^{59}$, me parece imprescindible insistir en una cosa: la necesidad de diferenciar entre el plazo de ejercicio de la acción (el año de prescripción al que alude el art. 59 ET a contar desde el momento en que la misma pudo ejercitarse, esto es, desde el impago) y el plazo durante el cual es exigible la responsabilidad del empresario principal o comitente (el año y los tres años a los que alude el art. 42 ET tras la finalización de la contrata). Así, el trabajador, durante la vigencia de la contrata, podrá dirigirse indistintamente contra cualquiera de los deudores solidarios (esto es, tanto contra el deudor "directo" como contra el empresario principal o comitente), eso sí, en la medida en que la "acción" que se ejercita no haya prescrito. Una vez haya finalizado la contrata, si las acciones no se entablan contra el empresario principal y solo se dirigen contra el contratista, las eventuales interrupciones solo operan respecto este último, y cuando haya pasado un año, la responsabilidad del empresario principal habrá desaparecido ${ }^{60}$. Todo ello porque, seguramente, la naturaleza de esta responsabilidad no sea exactamente una verdadera solidaridad, sino, más bien, una suerte de fianza solidaria ${ }^{61}$, por lo que su régimen jurídico no va a ser el recogido en los arts. 1137 y ss. Cc, sino el de los art. 1822 y ss. Cc; por esa misma razón, no resulta aplicable lo establecido en el art. 1974 Cc ("La interrupción de la prescripción de acciones en las obligaciones solidarias aprovecha o perjudica por igual a todos los acreedores y deudores"), pero sí lo previsto en el art. 1975 Cc ("La interrupción de la prescripción contra el deudor principal por reclamación judicial de la deuda surte efecto también contra su fiador; pero no perjudicará a esta la que se produzca por reclamaciones extrajudiciales del acreedor o reconocimientos privados del deudor").

La doctrina de suplicación venía manejado una lectura de este tipo desde hace unos cuantos años ${ }^{62}$. En este sentido, si analizamos los pronunciamientos dictados durante

\footnotetext{
${ }^{58}$ STSJ Cataluña de 15 de enero de 2010, rec. 6474/2008.

${ }^{59}$ Entre otros, Llano Sánchez, M. (1999: 262); Folguera Crespo, J. (2000: 223).

${ }^{60}$ En sentido diverso, Folguera Crespo, J. (2000: 224-225).

${ }^{61}$ Estaa idea sobre la verdadera naturaleza de la responsabilidad prevista en el art. 42 ET, que ya estaba en los estudios más clásicos en la materia -Rodríguez Piñero, M. (1972), "La regulación protectora del trabajo en contratas", Revista de Política Social, 93, p. 61-, aparece recogida en los trabajos de Llano Sánchez, M. (1999: 223) o Gala Durán, C. (2001: 244); asimismo, con un tratamiento muy detallado y magníficamente expuesto, también se encuentra presente en el de Gorelli Hernández, J. (2007: 171 y ss., especialmente, 184).

${ }^{62}$ Así, la STSJ Castilla-León Burgos de 16 de febrero de 2012, rec. 7/2012. Asimismo, la STSJ Galicia de 15 de marzo de 2010, rec. 1617/2006, afirmaba "Existe una relevante matización en cuanto a ese plazo anual al que se refiere el artículo 42 del ET, y es el hecho de que solo cabe exigir responsabilidad del empresario principal, durante el año siguiente a la terminación del encargo, a fin de no perpetuar en el tiempo su relación con la contrata impidiéndole ya no desvincularse de un encargo ya terminado, sino de situarse al margen de las múltiples y variadas reclamaciones, que por distintos incumplimientos por parte de la empresa contratista o subcontratista, pudieran tener lugar en el futuro. Y en aplicación de este plazo, ISSN: 2174-6419 Lex Social, vol. 10, núm. 1 (2020)
} 
los últimos diez años, no resultan inusuales las sentencias que diferenciaban los dos plazos y su distinta naturaleza, remarcando que el recogido en el art. 42 ET no es un plazo de prescripción, ni de caducidad, sino que se trata de un límite temporal a la exigibilidad de la responsabilidad ${ }^{63}$. Ahora bien, al tiempo de determinar los efectos que produce la reclamación dirigida contra el empleador "directo" respecto la responsabilidad del empresario principal, la respuesta era algo más confusa: en algunos casos se señalaba que las acciones entabladas contra el primero interrumpirían la prescripción respecto a dicho sujeto, pero no afectarían al deudor solidario ${ }^{64}$; en otros, se sostenía la necesidad de diferenciar antes y después de la extinción de la contrata, pues mientras la misma está vigente la interrupción afectaría a todos, en tanto que tras la extinción las acciones entabladas contra el deudor "directo" no tendrían efectos interruptivos respecto el deudor solidario $^{65}$; por último, en algún caso se afirmaba que la interrupción de la prescripción por el ejercicio de acciones contra el empleador afectaría a todos los deudores ${ }^{66}$.

Así las cosas, en este contexto, se dicta la STS de 5 de diciembre de 2017, rec. 2664/2015, que intenta unificar doctrina en la materia. Y lo hace, en el primero de los sentidos antes reseñados. En efecto, tras recordar el distinto origen que tienen las obligaciones del contratista y la responsabilidad del empresario principal o comitente, esta sentencia configura la responsabilidad de este último sujeto como una solidaridad impropia y niega que las acciones entabladas contra el empleador interrumpan la prescripción respecto aquél. Así, la sentencia afirma lo siguiente: "la responsabilidad solidaria de la empresa principal la impone el art. 42-2 del ET diferenciándola en su nacimiento, duración y exigencia de la de pago de salarios que regulan los artículos 1 , 26, 29 y 59 del ET en sus distintos particulares, lo que hace que no sea una obligación solidaria de las que el artículo 1137 del Código Civil contempla y que tenga un régimen en orden a la prescripción de esa responsabilidad diferente y al que resulta inaplicable el art. 1974 del Código Civil en orden a la interrupción de la prescripción por la reclamación a otro, como ya apuntó esta Sala, aunque fuese como "obiter dicta" en su sentencia de 20-9-2007 (R. 3539/2005 )". Esta misma orientación, a pesar de las críticas

la acción ejercitada contra la recurrente se encuentra prescrita, porque la norma específica que regula la cuestión, como acabamos de indicar, se contiene en el artículo 42 del ET, sin poderse aplicar, en este caso, el mecanismo interruptivo previsto en el artículo 1974 del Código Civil. Terminada la contrata para el actor, en la fecha en la que fue despedido esto es, 2 de noviembre de 2004, la recurrente solo podría responder solidariamente de las deudas salariales que pesan sobre la empresa codemandada y subcontratista, si se hubiera respetado el plazo de un año y no presentándose la demanda contra la empresa principal hasta el 22 de noviembre de 2005, el recurso de suplicación formulado prospera, con la consecuente revocación parcial de la sentencia de instancia".

${ }^{63}$ Así, por ejemplo, STSJ Navarra de 25 de mayo de 2015, rec. 209/2015; STSJ Comunidad Valenciana de 25 de junio de 2015, rec. 82/2015; SsTSJ País Vasco de 21 de julio de 2015, rec. 1456/2015 y de 1 de diciembre de 2015, rec. 2077/2015; STSJ Andalucía, Málaga, de 28 de abril de 2016, rec. 209/2016; STSJ Galicia de 22 de mayo de 2017, rec. 733/2017.

${ }^{64}$ STSJ Navarra de 25 de mayo de 2015, rec. 209/2015; SsTSJ País Vasco de 21 de julio de 2015, rec. 1456/2015 y de 1 de diciembre de 2015, rec. 2077/2015; STSJ Andalucía, Málaga, de 28 de abril de 2016, rec. 209/2016.

${ }^{65}$ STSJ Comunidad Valenciana de 25 de junio de 2015, rec. 82/2015; STSJ Galicia de 22 de mayo de 2017 , rec. $733 / 2017$.

${ }^{66}$ STSJ Islas Canarias, Tenerife, de 30 de septiembre de 2015, rec. 145/2015. 
vertidas en algunos estudios posteriores ${ }^{67}$, se aprecia en la doctrina de suplicación más reciente ${ }^{68}$.

\section{V.- UN BREVE APUNTE FINAL: INSUFICIENCIAS DEL SISTEMA Y PROPUESTAS DE MEJORA}

17.- El análisis efectuado en las páginas anteriores permite poner de manifiesto cómo, a pesar de la "estabilidad normativa" en el régimen de las responsabilidades vinculadas a los fenómenos de contratación y subcontratación de obras y servicios, las dudas interpretativas que genera el art. 42 ET siguen siendo muy relevantes.

17.1.- En efecto, los rasgos esenciales de este precepto no han sufrido grandes alteraciones desde el texto estatutario de 1980. Así, las previsiones contenidas en dicho texto normativo pasaron sin alteraciones al texto refundido de 1995. Con posterioridad, las reformas que incidieron en dicho artículo, llevadas a cabo en los años 2001, 2006 y 2012, ni modificaron su presupuesto aplicativo -la existencia de una contrata perteneciente a la propia actividad-, ni su consecuencia jurídica esencial -el establecimiento de una responsabilidad solidaria del comitente respecto las obligaciones salariales y de seguridad social contraídas por el contratista durante la vigencia de la contrata-, sino que tuvieron un alcance mucho más limitado, afectando tan sólo a ciertas cuestiones de carácter técnico-gramatical, a los derechos de información, consulta y participación ligados a estos fenómenos y al plazo de exigibilidad de la responsabilidad en materia de Seguridad Social.

17.2.- No obstante, a pesar del tiempo transcurrido y de la experiencia aplicativa acumulada, la norma sigue despertando interrogantes de importancia al tiempo de proceder a su interpretación: de entrada, ello sucede con la propia naturaleza de la responsabilidad impuesta; en segundo lugar, con el alcance objetivo de la misma, donde hay muchas partidas tanto en "materia salarial" como de "seguridad social" cuya inclusión o no en el ámbito protegido resulta dudosa o, en su caso, discutible; en tercer lugar, la funcionalidad y articulación del mecanismo de exoneración "limitada" que recoge el art. 42 ET, consistente en la solicitud de certificación negativa de descubiertos a la TGSS tampoco está libre de críticas; en fin, la extensión temporal de la responsabilidad impuesta no resulta clara, seguramente como consecuencia de que la naturaleza de la responsabilidad tampoco lo sea.

\footnotetext{
${ }^{67}$ López Sánchez, M ${ }^{\text {a }}$ C. (2018), "Régimen jurídico de la responsabilidad salarial en las contratas de "propia actividad": comentario a la STS de 5 de diciembre de 2017", en AEDTSS, Descentralización productiva: nuevas formas de trabajo y organización empresarial. XXVIII Congreso de Derecho del Trabajo y de la Seguridad Social, Madrid, CINCA (CD-ROM), pp. 4 y ss.; Dans Álvarez de Sotomayor, L. (2018), "Responsabilidad solidaria y prescripción de acciones de naturaleza salarial en la subcontratación de obras y servicios", en AEDTSS, Descentralización productiva: nuevas formas de trabajo y organización empresarial. XXVIII Congreso de Derecho del Trabajo y de la Seguridad Social, Madrid, CINCA (CDROM), pp. 5 y ss.

${ }^{68}$ STSJ Castilla León, Valladolid, de 4 de febrero de 2019, rec. 1967/2018 o STSJ Islas Canarias, Tenerife, de 9 de abril de 2019, rec. 368/2019.
} 
18.- Así las cosas, sería conveniente aprovechar una eventual reforma del precepto para incidir en este tipo de cuestiones y no sólo en las que planteaba la propuesta reformista presentada por el Grupo Socialista en septiembre de $2016^{69}$.

18.1.- De entrada, por lo que respecta a la naturaleza de la responsabilidad, al margen de la discusión sobre la oportunidad o no de sustituir la actual responsabilidad solidaria por la subsidiaria ${ }^{70}$, resultaría conveniente aclarar que, en realidad, estamos ante una fianza solidaria, con lo que ello implica en términos de régimen jurídico, de manera especial, en lo relativo al cálculo de los plazos y a la interrupción de la prescripción, así como en cuanto a las acciones con las que cuenta el comitente frente al contratista en los supuestos en que haya asumido la responsabilidad.

18.2.- Un segundo aspecto relacionado con los efectos en el que se debería incidir es el relativo al alcance de obligaciones asumidas. Y, en este punto, más allá de la posibilidad de acercar el régimen del art. $42 \mathrm{ET}$ al del art. $44 \mathrm{ET}$, en el sentido de no limitarlo a las obligaciones de "naturaleza salarial" -con las dificultades exegéticas que ello genera al tiempo de su concreción- y extenderlo a todo tipo de obligaciones, sería conveniente una regulación más ambiciosa que incluyese, adicionalmente, la equiparación de derechos entre los trabajadores de la empresa contratista y los de la empresa principal ${ }^{71}$. En efecto, el texto estatutario no contempla esa equiparación en condiciones, algo que sería deseable por diferentes razones: por un lado, una previsión de este tipo podría repercutir en el abandono de las razones "patológicas" que muchas veces influyen en el recurso a la descentralización productiva, ayudando a que esta técnica organizativa se emplease de una forma más pura, vinculada a razones de carácter "fisiológico", saneándose así el mercado de las contratas; por otro lado, una medida de este corte, unida a la reformulación del supuesto de hecho, se presenta como un importante correctivo a la proliferación de empresas multiservicios cuyas actuaciones quedan claramente al margen de las previsiones contenidas en la Ley 14/1994 y habitualmente también de las establecidas en el art. 42 ET, algo que sería beneficioso no sólo para los trabajadores implicados, sino también para una competencia leal entre ETTs y empresas multiservicios; en fin, esta medida se presenta, por lo demás, como una alternativa adecuada a ciertas proposiciones limitativas de la subcontratación que han proliferando en los medios especializados durante los últimos tiempos, al ser más respetuosa con la libertad de empresa reconocida constitucionalmente y que da amparo a la descentralización.

18.3.- Finalmente, por lo que respecta al deber de comprobación de descubiertos en materia de Seguridad Social y los efectos de la certificación emitida por la TGSS, debe señalarse que el sistema vigente, al margen de las deficiencias técnicas que presenta,

\footnotetext{
${ }^{69}$ Proposición de Ley 122/000015, presentada por el Grupo Socialista, sobre modificación del art. 42.1 del Estatuto de los Trabajadores para garantizar la igualdad en las condiciones laborales de los trabajadores subcontratados, BOCG de 9 septiembre de 2016.

${ }^{70}$ Al respecto, vid. Sala Franco, T.; Nores Torres, L. E.; Calvo Rodríguez, E. (2018), "La subcontratación”, en Sala Franco, T. (Dir.), Propuestas para un debate sobre la reforma laboral, Madrid, Edidciones Francis Lefebvre, 185.

${ }^{71}$ Nuevamente, vid. Sala Franco, T.; Nores Torres, L. E.; Calvo Rodríguez, E. (2018: 184 y 186). 
resulta abiertamente mejorable en distintos aspectos. Así, por ejemplo, la propia exoneración de responsabilidades en los supuestos de silencio por parte de la TGSS o, incluso, en los de certificación negativa, carece de sentido; en tales casos, sería más acertada su subsistencia, sin perjuicio de que las empresas hacia las que se ha extendido la responsabilidad pudieran dirigirse contra la Administración cuando el defectuoso funcionamiento de esta les hubiese generado responsabilidades. Por otra parte, un correcto funcionamiento de este deber de comprobación exigiría que tuviese un carácter cíclico, esto es, que se desarrolle de modo regular a lo largo de la vigencia de la contrata, como sucede en el ámbito tributario; de ese modo, la exoneración sería por el período certificado; e igualmente se podría pensar en buscar algún mecanismo exonerador respecto las obligaciones "salariales" ( o, laborales, si se extendiese a todas ellas), potenciando la inclusión de cláusulas contractuales que permitiesen rescindir la contrata cuando se detectasen los incumplimientos laborales.

\section{BIBLIOGRAFÍA CITADA}

Altés Tárrega, J. (1998), “La naturaleza jurídica de los salarios de tramitación: ¿al fin una cuestión resuelta?, Relaciones Laborales, 2, 122-133.

Aragón Sánchez, C. (2018), "Las responsabilidades de la empresa principal con respecto a las obligaciones de la empresa contratista en materia de Seguridad Social”, en AEDTSS, Descentralización productiva: nuevas formas de trabajo y organización empresarial. XXVIII Congreso de Derecho del Trabajo y de la Seguridad Social, Madrid, CINCA (CD-ROM), 12 pp.

Camps Ruiz, L. M. (2000), "La obligación empresarial de comprobar la solvencia del contratista o subcontratista: significado y consecuencias", en Blat Gimeno, F. et altri, Descentralización productiva y protección del trabajo en contratas. Estudios en recuerdo de Francisco Blat Gimeno, Valencia, Tirant lo Blanch, 243-258.

Dans Álvarez de Sotomayor, L. (2018), "Responsabilidad solidaria y prescripción de acciones de naturaleza salarial en la subcontratación de obras y servicios", en AEDTSS, Descentralización productiva: nuevas formas de trabajo y organización empresarial. XXVIII Congreso de Derecho del Trabajo y de la Seguridad Social, Madrid, CINCA (CD-ROM), 13 pp.

De Val Tena, A. L. (2018), "Exoneración de responsabilidad del empresario principal ante el incumplimiento de las obligaciones de Seguridad Social por os contratistas y subcontratistas: sobre los efectos de la certificación negativa de descubiertos librada por la Tesorería General de la Seguridad Social", en en AEDTSS, Descentralización productiva: nuevas formas de trabajo y organización empresarial. XXVIII Congreso de Derecho del Trabajo y de la Seguridad Social, Madrid, CINCA (CDROM), 12 pp. 
Fernández López, Ma . F. (2018), "Las responsabilidades empresariales en el ámbito del trabajo en contratas", en AEDTSS, Descentralización productiva: Nuevas formas de trabajo y organización empresarial. XXVIII Congreso de Derecho del Trabajo y de la Seguridad Social, Madrid, CINCA, 104-120.

Folguera Crespo, J. (2000), "La responsabilidad salarial del empresario en contratas y subcontratas: su alcance objetivo", en Blat Gimeno, F. et altri, Descentralización productiva y protección del trabajo en contratas. Estudios en recuerdo de Francisco Blat Gimeno, Valencia, Tirant lo Blanch, 195-226.

Gala Durán, C. (2001), "La responsabilidad en materia salarial en el ámbito de las contratas y subcontratas”, en Del Rey Guanter, S. (Dir.), Descentralización productiva y relaciones laborales: problemática jurídica actual, Valladolid, Lex Nova.

Gárate Castro, J. (1994), Los salarios de tramitación. Un estudio sobre las percepciones salariales unidas a la declaración de improcedencia o nulidad del despido, Madrid, ACARL.

García Murcia, J. (1981), “El trabajo en contratas y la cesión de mano de obra en el Estatuto de los Trabajadores”, Revista de Política Social, 130, 7-88.

Gorelli Hernández, J. (2007), La tutela de los trabajadores ante la descentralización productiva, Madrid, Grupo Difusión.

Llano Sánchez, M. (1999), Responsabilidad empresarial en las contratas y subcontratas, Madrid, La Ley.

López Gandía, J.; Tatay Puchades, C. (2000), "Contratas y subcontratas y responsabilidades de Seguridad Social", en Blat Gimeno, F. et altri, Descentralización productiva y protección del trabajo en contratas. Estudios en recuerdo de Francisco Blat Gimeno, Valencia, Tirant lo Blanch, 227-242.

López Sánchez, Ma . C. (2018), "Régimen jurídico de la responsabilidad salarial en las contratas de "propia actividad": comentario a la STS de 5 de diciembre de 2017", en AEDTSS, Descentralización productiva: nuevas formas de trabajo y organización empresarial. XXVIII Congreso de Derecho del Trabajo y de la Seguridad Social, Madrid, CINCA (CD-ROM), 12 pp.

López-Tarruella Martínez, F.; Viqueira Pérez, C. (2010), "Contratas y subcontratas: responsabilidad administrativa en materia de Seguridad Social”, en Blasco Pellicer, A. (Coord.), El empresario laboral, Valencia, Tirant lo Blanch, 461-475.

Luque Parra, M. (2001), "La responsabilidad empresarial en materia de Seguridad Social en el ámbito de las contratas y subcontratas de obras y servicios”, en Del Rey Guanter, S. (Dir.), Descentralización productiva y relaciones laborales: problemática jurídica actual, Valladolid, Lex Nova, 263-297.

Monereo Pérez, J. L. (1992), "El ámbito material de la responsabilidad en el trabajo en contratas. Las obligaciones "referidas" a la Seguridad Social", Relaciones Laborales-II, 265-309. 
Monereo Pérez, J. L. (1994), La responsabilidad empresarial en los procesos de subcontratación, Madrid, Ibidem.

Montoya Medina, D. (2004), Trabajo en contratas y protección de los trabajadores, Valencia, Tirant lo Blanch.

Montoya Medina, D. (2018), "Subcontratación de obras y servicios y responsabilidad administrativa en materia de Seguridad Social", en AEDTSS, Descentralización productiva: nuevas formas de trabajo y organización empresarial. XXVIII Congreso Nacional de Derecho del Trabajo y Seguridad Social, Madrid, CINCA (CD-ROM), 13 pp.

Nores Torres, L.E. (2004), El trabajo en contratas. La noción de "contrata de propia actividad", Valencia, Tirant lo Blanch.

Ramírez Martínez, J. M. (2002), "Las responsabilidades del empresario principal en las contratas y subcontratas", en Pedrajas Moreno, A. (Dir.), La externalización de actividades laborales (outsourcing): una visión multidisciplinar, Valladolid, Lex Nova, 147-171.

Rodríguez Piñero, M. (1972), "La regulación protectora del trabajo en contratas", Revista de Política Social, 93, 5-66.

Roqueta Buj, R. (2002), “Alcance temporal de las responsabilidades”, en Blat Gimeno, F. et altri, Descentralización productiva y protección del trabajo en contratas. Estudios en recuerdo de Francisco Blat Gimeno, Valencia, Tirant lo Blanch, 259-271.

Sala Franco, T.; Nores Torres, L. E.; Calvo Rodríguez, E. (2018), "La subcontratación”, en Sala Franco, T. (Dir.), Propuestas para un debate sobre la reforma laboral, Madrid, Ediciones, Francis Lefebvre, 177-186.

Viqueira Pérez, C. (2018), "Las responsabilidades laborales y de seguridad social en los supuestos de subcontratación”, en López Balaguer, M. (Coord.), Descentralización productiva y transformación del Derecho del Trabajo, Valencia, Tirant lo Blanch, 35-57. 